\title{
Letters
}

Website: bmj.com

Email: letters@bmj.com

\section{NHS database of reference costs is severely flawed}

EDITOR-The recent and growing emphasis on gaining a more rounded view of social care is to be welcomed. Assessments of efficiency (one of the dimensions of The NHS Performance Assessment Framework ${ }^{1}$ should take into account aspects of both quality and cost. Leaving aside the debate about how to assure and improve quality over time-the debate over clinical governance-there are sufficient difficulties in using routinely available cost information.

The reference costs database is one of the key sources of information. It is based on healthcare resource groups, which are the result of a systematic classification of acute care interventions into categories that are clinically distinct and have similar implications for resources. The intention is to provide a standardised method for comparing costs across hospitals: the more effective the standardisation process, the more likely it is that differences in costs reflect true differences in resource use. In theory, the reference costs provide information that permits management to make judgments about trusts' financial performance, or efficiency. ${ }^{2}$

Although, as with most of the centrally produced performance indicators, the publication of such information is surrounded by caveats about interpretation and an emphasis on statistical measures that take account of outliers, concern has to be expressed about the quality of data when the minimums and maximums for key healthcare resource groups are examined. The table has been constructed from the for themselves. framework. London: $\mathrm{DoH}, 1999$. tration 1995; 18:277-310. performance assessments in health and

Reference Costs 2000 database, ${ }^{2}$ and it shows the minimum and maximum costs quoted for healthcare resource groups that account for $\geqslant 25000$ finished consultant episodes (for elective inpatients only).

Even a cursory examination of the table highlights the ridiculous nature of the data that have been submitted by trusts (presumably after internal validation). For example, one trust has quoted a cost per healthcare resource group for a primary hip replacement of $£ 480$ (\$672); doubtless patients were handed a prosthesis to take home to fit

The pitfalls of performance indicators have been well documented." One is the inevitable tendency to focus on the average. It is pertinent to ask what those who commission healthcare services are doing with data that lie at the extremes. If the data were taken at face value, the total cost of these 363796 procedures would vary 42-fold depending on whether the minimum or maximum values were used. If such data are subjected to serious inquiry by the NHS, then will the distribution of costs quoted per healthcare resource group have narrowed considerably by the time the next database of reference costs is produced?

Brian Ferguson professor of health economics Nuffield Institute for Health, Leeds LS2 9PL

1 Department of Health. The NHS performance assessment

2 Department of Health. Reference costs 2000. London: DoH,

3 Smith P. On the unintended consequences of publishing performance data in the public sector. Int J Public Adminis-

Sample of reference costs $(£)$ submitted to NHS, $2000^{2}$

\begin{tabular}{llccc} 
HRG code & HRG label & $\begin{array}{c}\text { No of finished } \\
\text { consultant episodes }\end{array}$ & Minimum cost & Maximum cost \\
\hline B02 & Phacoemulsification with lens implant & 31869 & 98 & 3495 \\
\hline C22 & Nose procedures (category 3) & 29831 & 53 & 4129 \\
\hline C24 & Mouth or throat procedures (category 3)† & 83180 & 71 & 11221 \\
\hline F74 & $\begin{array}{l}\text { Inguinal, umbilical, or femoral hernia } \\
\text { repairs without complications for patients } \\
<70 \text { years }\end{array}$ & 26006 & 112 & 4524 \\
& Primary hip replacement & 33625 & 480 & 9337 \\
\hline H02 & Primary knee replacement & 28808 & 695 & 12921 \\
\hline H04 & Arthroscopy & 29487 & 167 & 6650 \\
\hline H10 & $\begin{array}{l}\text { Upper genital tract (intermediate } \\
\text { procedures) }\end{array}$ & 39309 & 164 & 10731 \\
\hline M06 & Upper genital tract (major procedures)§ & 61681 & 142 & 5531 \\
\hline M07 & & & \\
\hline
\end{tabular}

HRG=healthcare resource group. ${ }^{*}$ Category 3 procedures include septoplasty, nasal polypectomy, and submucous resection of nasal septum. †Category 3 procedures include tonsillectomy and adenoidectomy. łIntermediate procedures include culdotomy, drainage or aspiration of pouch of Douglas, endoscopic procedures on uterus and fallopian tubes, and ligation and clipping of fallopian tubes. §Major procedures include abdominal and vaginal hysterectomy and excision of the uterus.

\section{Approach to surgery in United Kingdom should be shaken up}

EDITOR-With respect to the article by Wilmore and Kehlet on the management of patients in fast track surgery, the NHS needs to overhaul its surgical model completely. ${ }^{1}$ Although there will always be a need for hospital based surgery for major procedures and for less major procedures in higher risk patients, many procedures could be performed more efficiently in outpatient surgical facilities.

When my father reached the top of the waiting list and had elective wrist surgery in an NHS hospital, he spent a night in hospital before surgery to provide for an anaesthetic preoperative assessment, which took place the following morning, and another after surgery. And the procedure might still have been cancelled on the day because of a lack of inpatient beds or theatre space. This experience is not uncommon.

In the United States someone would be asking: "Who is paying for this?" Freestanding, often independent, ambulatory surgery centres have increased in number, to the point where they often threaten the viability of nearby hospitals. But the NHS model of centrally funded care renders this competition financially irrelevant and would allow hospital surgical units to focus on true hospital cases.

I codirect and provide anaesthesia and acute and chronic pain management services in one such facility. It is extremely efficient (and profitable for the shareholders), and the care provided is of the highest standard that I have seen in 19 years of medicine and surgery, much of it in the United Kingdom. The range of care includes orthopaedics (joint arthroscopy, cruciate ligament and shoulder reconstructions, extensive arm surgery, and lumbar and cervical spinal surgery), general surgery ("lumps and bumps," laparoscopic cholecystectomy, and hernia repair), cosmetic surgery (mostly reconstructions after mastectomy), and invasive pain management. Similar facilities nearby cater for most of the common ear, nose, and throat, gynaecological, and ophthalmological procedures. In four theatres and one fluoroscopy room we conduct 250 surgical and 200 interventional pain management procedures per month, without operating weekends or evenings or yet running at maximum capacity. Our high response to mail surveys of patients and our routine follow up telephone calls tell us that patients and families appreciate the excellent care; the doctors enjoy operating here 
because things work well and their patients like it; and there is a low turnover of staff because they are content, working in a small, non-hospital environment where high standards of care are demanded. The NHS leadership should rethink surgery: the ambulatory surgery centre model works in terms of cost and quality of care and should be where all suitable surgery is performed in the United Kingdom.

Philip A Isaac staff anaesthesiologist

Diplomate American Board of Anesthesiologists, St Anthony North Ambulatory Surgery Center, 6205 North Santa Fe, Suite 100, Oklahoma City 73118 USA

1 Wilmore DW, Kehlet H. Management of patients in fast track surgery. BMJ 2001;322:473-6. (24 February.)

\section{Stakeholder health insurance}

\section{Time for evidence based policy analysis}

EDITOR - In their commentary to my article Dixon and Appleby seem to have been deeply taken aback by my claim that the NHS fails the poorest people in society and responded with a personal attack, asserting: "Green's aims are disingenuous at best." The ordinary meaning of disingenuous is to be insincere or to have secret motives.

The essence of my argument is this: the rich can always take care of themselves and it is the government's responsibility to ensure that the poorest people have access to a reasonable standard of health care. But what should that standard be? Should it be perceived as a minimum or core standard, in which case it will always be possible to claim that it is too low? Or should it be seen as comprehensive, in which case it will be unachievable, as the BMA's recent inquiry acknowledged.

My proposed scheme tries to deal with this conundrum by removing the decision about the appropriate standard from the political domain. Instead, the standard guaranteed by the government should be linked to the choices made on their own behalf by people with middle incomes. I propose that the government should guarantee this standard for everyone. Yes, the rich will be able to afford more, but they can do so now under the NHS. That will not change, but the deeper reality is that all healthcare systems must be affordable, whether they are paid for by taxes on earnings or by private payments made from earnings.

My claim is that, compared with the standard currently provided by the NHS, such a guarantee would be a substantial improvement for the poorest people in the United Kingdom. In addition, the guaranteed standard will rise with growing incomes because it is linked to the personal market choices of middle income earners. It will not be a residual or second class standard.

The evidence for this claim is that the social insurance systems of France, Germany, and the Netherlands already work in a similar manner and it should be possible to put this case in a learned journal without being accused of bad faith. The King's Fund has been very keen to encourage the practice of evidence based medicine by doctors. How about some evidence based public policy analysis from Dixon and Appleby?

David G Green director

Institute for the Study of Civil Society, Elizabeth

House, London SE1 7NQ

david.green@civitas.org.uk

1 Green D. Stakeholder health insurance: empowering the poorest patients [with commentary by J Dixon, J Appleby] BMJ 2001:322:786-9. (31 March.)

** We apologise to Dr Green for allowing through the phrase "Green's aims are disengenuous at best." We certainly do not believe that Dr Green has secret motives.-RICHARD SMITH, editor, $B M J$

\section{Commentary is disappointing}

EDIToR-Dixon and Appleby's commentary on Green's article is disappointing.

Firstly, to turn disagreements over policy into personal accusations of dishonesty is wrong, making it hard to carry on a civil discussion.

Secondly, I am struck by their complacency-"What's the problem?"-as if all is for the best in this best of all possible worlds. That view is not tenable, especially in the wake of the secretary of state's plan for reform of the NHS. ${ }^{2}$ The secretary of state personally wrote to me: "The NHS is a 1940s system operating in a 21st century world. It has a lack of national standards, old fashioned demarcations between staff and barriers between services, a lack of clear incentives and levers to improve performance [and] over centralization and disempowered patients." These frank statements suggest that he is sincere and serious about exposing the problems and proposing solutions.

Dixon and Appleby write: "Competition is instrumental, so a lack of it is not itself a problem." Generally, competition has proved to be the only institution that has been able to motivate sustained improvement in economic performance. But, as illustrated by electricity in California, trains in Britain, and the internal market in the NHS, not any competition will do. There must be appropriate institutions, including regulatory frameworks. ${ }^{3}$ Green argues that Britain ought to find a way to bring competition into health services and proposes a rational design for doing so.

The secretary of state proposes to motivate improvement by harassment from the centre. Some hospitals are to be designated "green light" and left alone, some "yellow light" to be given warning, and others "red light," which "will be subject to a bewildering gang of possible bodies who will be able to manage their performance .... [which is] messy and predatory performance management." I share Dixon and Dewar's reservations. Other models should be examined in case this government's model fails.

Dixon and Appleby argue that the NHS does not fail the poorest of society because "regardless of income and ability to pay, the comprehensive benefits of the NHS are available to all." Their defence is that the misery is spread equally. In fact, there are wide inequalities, and the poor are unlikely to get even average NHS care.

Green argues that his plan will make everybody better off because those who opt out of NHS care will leave behind a part of their share of NHS funds, which will increase the per capita spending on those who remain in the NHS. More money would be brought into health care without raising taxes. Moreover, improved performance in the competitive sector would set higher standards and expectations for the NHS

Dixon and Appleby doubt that there would be many takers for the stakeholder option because currently only $11 \%$ of the British population is covered by private health insurance. One important reason for this is that there is no tax subsidy.

Efficiency is much more than a matter of low administrative costs. The NHS is grievously undermanaged. It lacks basic data on cost, quality, and performance. ${ }^{3}$ A well run large scale competitive model could be run with very low administrative costs.

Alain C Enthoven Marriner $S$ Eccles professor of public and private management (emeritus) Graduate School of Business, Stanford, CA 94305, USA

enthoven_alain@gsb.stanford.edu

1 Green D. Stakeholder health insurance: empowering the poorest patients [with commentary by J Dixon, J Appleby] poorest patients [with commentar

2 Department of Health. The NHS plan. A plan for investment A plan for reform. London: Stationery Office, 2000. (www.nhs.uk/nhsplan)

3 Enthoven AC. In pursuit of an improving National Health Service. The 1999 Rock Carling Fellowship. London: Nuffield Trust, 1999

4 Dixon J, Dewar S. The NHS Plan: as good as it gets-make the most of it. BMJ 2000;321:315-6.

\section{Authors' reply}

EDITOR-Green claims that stakeholder health insurance would improve health care for the poorest patients by allowing them the option to pay extra-to buy stakeholder health insurance. But is it realistic to believe that the poorest could or would pay extra? Evidence suggests not. Green is clearly not interested in social equity - he does not show that the distribution of contributions to his new system would be more or less equitable than is the case now.

If those who are comparatively well off took a tax subsidy out of the NHS, then less would remain for those who are sicker and those who remained in the NHS. The NHS would become a poorer quality service, dealing with a higher proportion of patients with significant health needs. Contrary to Green's claims, stakeholder health insurance would disempower the poorest.

Green says there should be a guaranteed core standard of service for everyone-in the NHS or no. He suggests it should be a political decision linked to the preferences of those who opt for stakeholder health insurance. Why is this appropriate? He also does not make clear quite how this would work. Would government be shamed into ensuring that standards of quality in the NHS were as high as in the private sector 
hospitals used by those with stakeholder insurance? Green suggests yes, citing countries with a plurality of purchasers and providers, such as France and Germany. But he is not more forthcoming with evidence. Would the government be more likely to set a minimum standard to keep costs under control? History suggests this is more likely.

Enthoven accuses us of complacency because we ask what is the problem? This was not rhetorical, rather, a way to identify to readers exactly what problem potential reformers of the NHS are trying to solve. Sadly it is often not obvious.

We generally agree with Enthoven that competition can be a highly effective stimulant to improve economic performance. But in public services competition can fail to strike the right balance between multiple objectives such as social equity, humanity of care, responsiveness, and so on. We do not agree that it is doubtful that the poor get even average NHS care-a recent review examines the evidence. ${ }^{1}$ The pertinent point to argue is whether Green's proposals offer an improvement to now. We argue the reverse for reasons already outlined.

Finally, we believe that there is an absence of a proper diagnosis as to why performance in service delivery is inadequate in parts of the NHS. Without this understanding the NHS is prey to perhaps intellectually interesting, but inevitably half baked solutions, whether they come from think tanks or, just as frequently, from the government itself.

Jennifer Dixon director, health care polic

John Appleby director, health system

King's Fund, London W1M OAN

1 Dixon J. What is the hard evidence on the performance of "mainstream"health services serving deprived compared to nondeprived areas in England? Report for the Social Exclusion Unit. London: King's Fund, 2000

\section{Warning to GMC}

\section{Patients should come first}

Editor-How interesting that Heath overlooks the General Medical Council's primary responsibility-protecting patients. ${ }^{1}$ Everything else flows from this duty. To relate empowering patients to political abuse and coercion seems disingenuous. Why elevate to top priority protecting doctors' freedom to conduct their practice however they see fit? It suggests a desire to thwart the government's goal of putting patients, their views, and their interests at the heart of the NHS.

Most doctors also come from a relatively narrow, affluent, and well educated section of society. Lay people contributing to medical bodies need comparable educational attributes to hold their own in debate with health professionals. This inevitably limits eligibility. That's life. Moreover, doctors who polled the most votes at a recent GMC by-election included one once struck off for her attitude to patients and colleagues and another fined for carrying out surgery without consent. This hardly makes the argu- ment for election as preferable to appointment.

We can explore the feasibility of the patient movement and the voluntary sector electing non-professionals (a better expression than lay people, with its flavour of second class citizens) to the GMC. Community health councils have provided a precedent for such a system.

Roger M Goss director

Patient Concern, London SW5 9FY

rogerconcern@hotmail.com

1 Heath I. A warning to the GMC. BMJ 2001;322:433. (17 February.

\section{Doctors are part of an economic hegemony}

EDITOR-Heath is quite right to underline the long and dishonourable history of the political subversion of medicine. ${ }^{1}$ She seems to assume, however, that current medical practice is untainted by malign forces. As doctors we are certainly control agents, representatives if you like of our political masters and an increasing hegemony that dictates the manner in which we practise as doctors.

For proof she need look no further than the $B M J$, to which she has been an editoria adviser and frequent contributor. Before the first editorial in the issue of 17 February, there are six full page adverts for new drugs (celecoxib, linezolid, rosiglitazone, tirofiban, and risedronate in this order). We are asked to believe in the editorial integrity of this magazine, yet, to date, only rosiglitazone has respectability. Who controls the $B M$ /s advertising policy? We need an open debate on the independence of all our representative bodies, not just the General Medical Council.

Jim Hardy general practitioner

Bethnal Green Health Centre, London E2 6LI jameshardy@doctors.net.uk

1 Heath I. A warning to the GMC. BMJ 2001;322:433. (17 February.)

\section{Rights involve responsibilities for patients}

Doctors must not generally pass personal information about patients to others without consent

EDITOR-Doll and Peto suggest that the right to medical care should generally continue to include the responsibility to allow the information gained during its course to be used for the benefit of others who develop a similar disease or are at risk of developing it.

This is based on the false premise that such a responsibility exists and disregards the requirements of the law. Doctors, just like other citizens, are subject to legislation and the common law, which require consent to the disclosure of identifiable health information. It is clear not only from case law but from the Data Protection Act 1998 and the Human Rights Act 1998 that as a society we accord considerable rights to the individual, including the right to privacy and autonomy.

The health departments of the United Kingdom are currently introducing measures to ensure that doctors can work within the law without jeopardising research. In England and Wales the Health and Social Care Bill will provide transitional arrangements for disclosure of information, at the direction of the secretary of state, that would otherwise be unlawful. It is not for the General Medical Council, or individual doctors, to decide on what terms patients receive care in the NHS, or when the requirements of the courts and parliament can be disregarded.

The General Medical Council fully recognises the importance of research and public health monitoring and encourages doctors to provide relevant information to registries, to bodies monitoring the safety of medicines, and for other public health purposes. Nevertheless, we do not believe that it is acceptable, either legally or morally, for doctors to pass personal information about patients on to others without the patients' knowledge or consent, except where there is an over-riding public interest or the law requires it.

Patients have a right to know when others want to be informed of, and store intimate details about their private lives. In many cases they have a right to give or withhold consent to these disclosures.

Cyril Chantler chairman, standards committee General Medical Council, London W1N 6JE JTupper@gmc-uk.org

1 Doll R, Peto R. Rights involve responsibilities for patients. BMJ 2001;322:730. (24 March.)

Research ethics committees will approve any protocol unless there are good reasons not to

EDitor-Doll and Peto complain that the need for a patient's consent hinders research, particularly epidemiological studies. ${ }^{1}$ Regrettably, the increasing attention paid to patients' rights has been brought about by the cavalier attitude of many researchers towards the use of patientidentifiable data over the past three decades. Data have not been anonymised when they could easily have been and have been used for purposes that were not in the original research protocol. For these and other reasons, research ethics committees and the principles of informed consent for the use of patient-identifiable data have had to be introduced.

If a researcher can make a good case for collecting data without consent then a research ethics committee will give it due consideration. But the research community will have to convince many people on the committee that it will handle the data only in accordance with the original submitted protocol and that disciplinary action will be taken against those breaching the rules; only then will the proposal be accepted.

It is as unethical to hinder legitimate research as it is to permit the use of data for which consent has not been given. Those of 
us responsible for protecting patients' interests are well aware of this. Research ethics committees are not bound by advice issued by the General Medical Council or any body other than the Department of Health; they will approve any protocol unless there are good reasons for them not to (despite the perceptions of most researchers).

Terence W Wiseman chairman, local research ethics committee

Market Rasen, Lincolnshire LN8 3BJ

wiseman@conwayhouse.com

1 Doll R, Peto R. Rights involve responsibilities for patients. BMJ 2001;322:730. (24 March.)

\section{Human papillomavirus testing}

\section{Authors' comments}

EDITOR-In This Week in the BMJ of 14 April our study of human papillomavirus testing and the management of women with mildly abnormal cervical smears is described as an NHS pilot ${ }^{1}$; it was not. In the accompanying editorial Manos expressed surprise that we advised caution in the clinical use of this test despite evidence for its role in managing women with borderline cervical smears. ${ }^{2}$ We intended the context of our advice to be that of our paper: the management of women with borderline or mildly dyskaryotic smears.

As we stated, although there is evidence from the UnitedStates thathumanpapillomavirus testing is useful in triaging the equivalent of borderline change, such testing has limited potential in triaging the equivalent of mild dyskaryosis (because of high positivity for papillomavirus (83\%)). ${ }^{3}$ Caution would seem reasonable if these two types of mild abnormality are being considered together (as in the NHS pilot scheme based in England) rather than separately (as in the United States). We were disappointed that Manos's editorial said little about mild dyskaryosis.

We found a prevalence of papillomavirus $(41 \%)$ and a test sensitivity $(86 \%)$ for those with only borderline smears that were comparable to those of the Kaiser Permanente study mentioned by Manos, but we found a lower sensitivity (92\%) and negative predictive value $(89 \%)$ for younger women (29 subjects) than it reported. We confirmed high positivity for papillomavirus (75\%) among those with only mild dyskaryosis, with a low positive predictive value $(39 \%)$; the highest negative predictive value in this subgroup was 92\% among 68 younger women (1 pg/ml cut off point).

We agree that our study design contributed to the prevalence of high grade disease $(35 \%)$, but this figure is consistent with that in previous reports. ${ }^{4}$ Our subjects had had persistent mildly abnormal smears before being referred for colposcopy (reflecting United Kingdom guidelines). Although high grade lesions associated with such smears tend to be small (emphasising the need for accurate diagnosis), ${ }^{4}$ no evidence exists that persistence in itself selects lesions that are difficult to sample or identify. We used large loop excision of the transformation zone because it is more accurate than colposcopic biopsy (and yields more high grade disease) and allows treatment at the first visit. ${ }^{5}$ Each specimen was examined by at least two pathologists (with initial reporting by at least one and then review by GR).

We believe that human papillomavirus testing may prove useful in cervical screening in certain defined contexts, which may involve different methodologies including the polymerase chain reaction. We await the results of the NHS pilot scheme.

Gemma Rebello consultant cytopathologist Colposcopy Clinic, Royal Infirmary of Edinburgh, Lothian University Hospitals NHS Trust, Edinburgh EH3 9YW

Nick Hallam consultant virologist Regional Clinical Virology Laboratory, City Hospital, Lothian University Hospitals NHS Trust, Edinburgh EH10 5SB

George Smart consultant gynaecologist David Farquharson patient services director, reproductive medicine

Jane McCafferty colposcopy sister

Colposcopy Clinic, Royal Infirmary of Edinburgh

Competing interests: GR and $\mathrm{NH}$ have been sponsored by Digene Diagnostics to attend several conferences.

1 Rebello G, Hallam N, Smart G, Farquharson D, McCaffert J. Human papillomavirus testing and the management of women with mildly abnormal cervical smears: an observational study. BMJ 2001;322:893-4. (14 April.)

2 Manos MM. HPV testing for clarifying borderline cervica smear results. BMJ 2001;322:878-9. (14 April.)

Atypical Squamous Cells of Undetermined Significance Low-Grade Squamous Intraepithelial Lesions Triage Study (ALTS) Group. Human papillomavirus testing for triage of women with cytologic evidence of low-grade squamous intraepithelial lesions: baseline data from a domized trial J Natl Cancer Inst 2000;92:397-402.

domized trial. J Natl Cancer Inst 2000,92.997-402. . . , Duncan I. Inaccuracy of cytologic diagnosis in high grade squamo 5 Howe DT, Vincenti AC. Is large loop excision of the transformation zone (LLETZ) more accurate than colposcopically directed punch biopsy in the diagnosis of cervica intraepithelial neoplasia? Br J Obstet Gynaecol 1991;98: $588-91$

Effectiveness of testing for high risk HPV for triage of low grade abnormal smears is being assessed in TOMBOLA trial

EDITOR-Cuzick et al have reported that testing for human papillomavirus might be used for triage of women with low grade abnormal smears in the NHS cervical screening programmes. $^{1}$ This would help identify women with high grade pre-cancer, and minimise investigations and overtreatment of other women. Rebello et al and Manos highlight the incompleteness and inconsistencies of the evidence on the possible value of human papillomavirus testing in triage. ${ }^{23}$

Apart from a small trial by Lytwyn et $\mathrm{al}^{4}{ }^{4}$ evidence regarding human papillomavirus testing in triage is indirect. ${ }^{1}$ For direct evidence, Manos draws attention to forthcoming prospective data from the ALTS trial of the management of women with atypical squamous cells of undetermined significance. ${ }^{3}$ But the results of that trial are unlikely to be generalisable to the NHS screening programme: screening populations and protocols, and cytological classification systems and the definition of abnormalities, differ between the United Kingdom and the United States.
Rebello et al refer to the pilot implementation of human papillomavirus testing in the NHS, which seems to be of process rather than outcome. ${ }^{2}$ A large randomised controlled trial (the trial of management of borderline and other low grade abnormal smears-TOMBOLA) is now under way in the United Kingdom, addressing the effectiveness and efficiency of human papillomavirus testing in the triage of women with borderline nuclear abnormalities and mild dyskaryosis.

The trial is comparing management by cytological surveillance with initial colposcopy, and "see and treat" with biopsy and selective recall among women randomised to colposcopy. A major difficulty in designing the trial was that there is no treatment for human papillomavirus infection. If management policy was based on the result of the test, the effects of infection and management would be confounded. Our solution is to test for interactions between human papillomavirus and the alternative management policies in relation to cervical intraepithelial neoplasia grades 2 and 3 or more severe disease. Psychosocial and health economic outcomes are being evaluated.

Manos emphasised the importance of accurate classification of pathological outcome. ${ }^{3}$ To this end, our trial includes rigorous quality control, consensus review, and markers of high grade pre-cancer. We intend to compare operational and economic aspects of different tests to determine the optimal one should testing for human papillomavirus prove effective in triage.

Decisions about implementing high risk- human papillomavirus testing in the NHS cervical screening programmes must be based on evidence from large randomised trials with rigorous pathological end points and evaluation of psychosocial impact and costs. Indirect evidence must also be critically appraised adequately.

Julian Little professor of epidemiology

Epidemiology Group, Department of Medicine and Therapeutics, University of Aberdeen, Aberdeen AB25 2ZD

j.little@abdn.ac.uk

On behalf of the TOMBOLA Group

1 Cuzick J, Sasieni P, Davies P, Adams J Normand C, Frate A, et al. A systematic review of the role of human papillomavirus testing within a cervical screening programme. Health Technol Assess 1999.3.

2 Rebello G, Hallam N, Smart G, Farquharson D, McCafferty $\mathrm{J}$. Human papillomavirus testing and the management of women with mildly abnormal cervical smears: an observational study. BMJ 2001;322:893-4. (14 April.)

3 Manos MM. HPV testing for clarifying borderline cervical smear results. BMJ 2001;322:878-9. (14 April.)

4 Lytwyn A, Sellors JW, Mahony JB, Daya D, Chapwan W, Ellis N, et al. Comparison of human papillomavirus DNA testing and repeat Papanicolaou test in women with low-grade cervical cytologic abnormalities: a randomised trial. CMAJ 2000;163:701-7.

5 Philips Z, Whynes D. Health economics of TOMBOLA: trial of management of borderline and other low-grade abnormal smears. Eur J Cancer 2000;36(suppl 3):S5.

\section{The People's Health Assembly}

EDITOR-The editorial by Chowdhury and Rowson refers to the enduring relevance of primary healthcare principles established in Alma Ata to the insufficient resources avail- 
able to support primary healthcare action in poor communities, and to the need for a shared vision of health for all.

Much of our work at the World Health Organization focuses on increasing resources to improve health for the world's 3 billion poor people. In December the Okinawa conference on infectious diseasesattended by representatives of governments and non-governmental organisations from developing countries, international agencies, research groups, and other interested parties-laid out strategies to combat the main health conditions that cause and perpetuate poverty. It followed up on statements made by $\mathrm{G} 8$ leaders on the critical importance of health in the context of strategies for poverty reduction.

Poor people should have more opportunity to access the services, commodities, and information that they need for better health. Organisations in the private and public sectors need to cooperate. The factors in society that increase people's vulnerability to disease should be tackled. Healthy public policies, in employment, in housing, in trade, and in education, are needed. Health must be properly located within national poverty reduction strategies.

The forces of globalisation must work for the poor, so that they enjoy better health as a result of increased crossborder movements of products, people, services, and information. We will seek new incentives for research and development, for new vaccines, better medicines, and more reliable diagnostics. We will build on the converging interests of global public health, the research based pharmaceutical industry, and those who set the rules for international trade.

We will support the protection of patents as a necessary and effective incentive for research and development, so that patents are managed in ways that benefit the patent holders and the public. We will enable countries to access information on all the potential options for increasing people's access to essential medicines, including tiered pricing when they are on patent.

We will re-examine arrangements through which development assistance contributes to better health. I am inspired by the suggestion of an emerging popular movement for health for all. I shall continue to ensure that the WHO works, as encouraged by its member states, for equitable health outcomes, and seek ways to work effectively with other groups with similar values, especially if they may be able to make significant contributions to the fulfilment of these outcomes and to the empowerment of those whose lives are blighted by illness and suffering.

Gro Harlem Brundtland director-general World Health Organization, CH-1211 Geneva 27, Switzerland

nabarrod@who.ch

1 Chowdhury Z, Rowson M. People's Health Assembly. BMJ 2000;321:1361-12 (2 December.)

\section{Peer led programme for asthma education in adolescents}

Issues of design and analysis are crucial in cluster randomised trials

EDITOR-We have concerns about the design and analysis of Shah et al's cluster randomised trial of a peer led education programme for asthma. ${ }^{1}$ Neither the printed nor the (longer) electronic version mentioned how clustering was accounted for in the trial design. The sample size was not justified-neither the number of clusters (six) nor numbers of children in them. This may seem unimportant since confidence intervals were provided for the comparisons between arms, but the omission is crucial.

The authors did not specify the magnitude of differences considered in advance as clinically important. The small intracluster correlations observed could just be fortuitous. With so few clusters, any estimate of between-cluster variance (and hence intracluster correlation) will be extremely imprecise. Without proper details of trial design, the danger of publication bias remains, where a study with low power is more likely to be published when significance is attained. The widths of the comparative confidence intervals are not reassuring here

It is unlikely that a fully considered trial design would include only six clusters, with apparently no attention being paid to stratification, given the sex and year imbalances. ${ }^{2}$ Important information was also omitted regarding the analysis plan, with betweenarm comparisons in table 2 for quality of life as a total score and three subdomains. Only the electronic version states that the total score was the primary outcome.

More fundamentally, comparisons for each of the four outcomes were presented first for all children and then for four subgroups (males and females in years 7 and 10). Separate tests for subgroups rather than formal interaction tests are highly prone to false positive results. There was no indication that these subgroup analyses were established in advance, nor specifically whether others were conducted. The analysis section of the electronic version refers to sex and year as potential confounders, not effect modifiers.

If the principle of "electronic long, paper short" publishing is to be successful, it is important that short versions do not omit crucial methodological information. It cannot be assumed that all readers have access to electronic versions, and Plummer has commented on the paper (in his rapid response) without apparently checking the long version.

We appreciate that the exclusion of cluster adjusted results was justified here on grounds of space, ${ }^{4}$ but we contend that issues of design and analysis are vital in cluster randomised trials and should have been mentioned in the short version.
Tim J Peters reader in medical statistics Department of Social Medicine, University of Bristol, Bristol BS8 2PR tim.peters@bristol.ac.uk

Anna Graham clinical research fellow Chris Salisbury senior lecturer in general practice Division of Primary Health Care, University of Bristol

Laurence Moore senior research fellow Cardiff School of Social Sciences, Cardiff University, Cardiff CF10 3WT

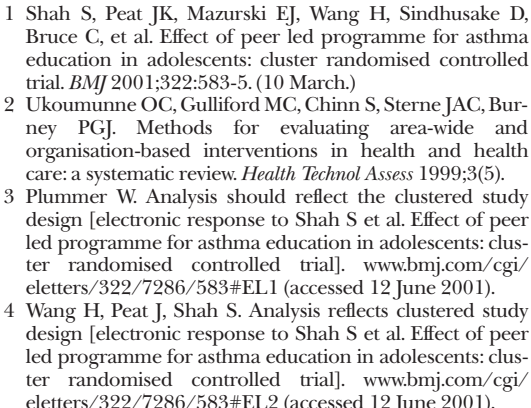

1 Shah S, Peat JK, Mazurski EJ, Wang H, Sindhusake D, Bruce C, et al. Effect of peer led programme for asthma education in adolescents: cluster randomised controlled education in adolescents: cluster rand
trial. BMJ 2001;322:583-5. (10 March.)

2 Ukoumunne OC, Gulliford MC, Chinn S, Sterne JAC, Burney PGJ. Methods for evaluating area-wide and organisation-based interventions in health and health care: a systematic review. Health Technol Assess 1999;3(5).

3 Plummer W. Analysis should reflect the clustered study design [electronic response to Shah $S$ et al. Effect of peer led programme for asthma education in adolescents: cluster randomised controlled trial]. www.bmj.com/cgi/ eletters/322/7286/583\#EL1 (accessed 12 June 2001).

4 Wang H, Peat J, Shah S. Analysis reflects clustered study design [electronic response to Shah S et al. Effect of peer led programme for asthma education in adolescents: cluster randomised controlled trial]. wwwbmj.com/cgi/ ter randonised cons\# 2 ( 12 June 2001).

\section{Papers describing cluster randomised trials must be peer reviewed by} statisticians

EDIToR-We believe that Shah et al's paper on the effect of a peer led programme for asthma education in adolescents has serious weaknesses. ${ }^{1}$ The authors seem not to have taken account of articles highlighting issues surrounding the design and analysis of cluster randomised trials..$^{2-4}$ There is no evidence from the paper of a sample size calculation, let alone one that allows for clustering.

A cluster randomised study generally lacks power compared with a non-clustered study of the same size, due to homogeneity of individuals within clusters. Not accounting for this in the analysis could alter the authors' conclusions. The variance of an estimate from a cluster randomised trial is increased relative to the variance in a non-clustered design by a factor of $1+(\langle\mathrm{n}\rangle-1) \rho$, where $\langle\mathrm{n}\rangle$ is the average cluster size and $\rho$, the intracluster correlation coefficient, is a measure of the betweencluster variation in the outcome being considered.

In this study, average cluster size is about 40. We cannot estimate $\rho$ accurately, but even a modest (in these circumstances) $\rho$ of 0.01 would lead to a $40 \%$ increase in variance and hence an increase in standard error of about $20 \%$. This could alter the conclusions concerning the quality of life measure.

We note from the information on prepublication history that although there was a statistician on the hanging committee, this paper was not reviewed by a statistician. We recommend that to avoid weaknesses in future publications of this sort, all papers describing cluster randomised trials are in future peer reviewed by a statistician, preferably one with experience in this field.

Martin Underwood senior lecturer

Sandra Eldridge statistician

Barts and the London, Queen Mary's School of

Medicine and Dentistry, London E1 4NS 
1 Shah S, Peat JK, Mazurski EJ, Wang H, Sindhusake D, Bruce C, et al. Effect of peer led programme for asthma education in adolescents: cluster randomised controlled trial. BMJ 2001;322:583-5. (10 March.)

2 Kerry SM, Bland JM. Statistics notes: The intracluster correlation coefficient in cluster randomisation. $B M J$ 1998;316:1455

3 Kerry SM, Bland JM. Statistics notes: Sample size in cluster randomisation. $B M J$ 1998;316:549.

4 Kerry SM, Bland JM. Statistics notes: Analysis of a trial randomised in clusters. $B M J$ 1998:316:54.

\section{Authors' reply}

EDITOR-In his rapid response to our paper on bmj.com Plummer emphasises the pitfalls that can arise in the statistical analysis of cluster randomisation studies. ${ }^{1}$ In fact, we did calculate intraclass correlations to explore any effects due to clustering, although space precluded us from including both these data and more extensive withinschool baseline data. For all outcomes, the values were exceedingly small-for example, those for the mean differences in quality of life scores were $<0.002$ for all domains. Clearly, values such as this have a negligible effect on $P$ values.

Randomisation by clusters was necessary to avoid contamination of the control group and to make the intervention feasible. This is a strength of the design that adds to the generalisability of the results. It was considerably easier to educate a whole class about asthma than to identify students with asthma and offer separate classes for them. This strategy also provides the opportunity for asthma education to be incorporated into the school curriculum. ${ }^{23}$

We conducted a trial of an important intervention (asthma education) in a problematic group (adolescents in a rural high school) and measured outcomes that are acknowledged to be relevant to people with asthma (quality of life, asthma attacks, and school absenteeism). We found that a peer led approach to asthma education led to beneficial results.

Although Peters (letter here in the paper journal) and Plummer $^{1}$ find important omissions from the analysis plan in the written version of the paper, these are reported in the electronic version. The sample size calculation and justification are reported in our study protocol, which was the basis for the peer reviewed funding application. Journals seldom publish these. We based these calculations on an earlier study, in which we measured quality of life before and after the intervention in a smaller number of adolescents. ${ }^{2}$ A priori we chose the subgroups of male/female and years 7 and 10 because of our prior results, and because of the design of the intervention (year 10 students are active participants in the education process, whereas year 7 students are passive recipients). ${ }^{34}$

Finally, there are clear advantages to electronic publication. As experience with the principle of "electronic long, paper short" publishing grows, we should see increasingly detailed electronic publications that allow full description of the research process and additional results. This system works well with the electronic versions of systematic reviews in the Cochrane library.

From this correspondence we have learnt that, given the opportunity of electronic publication, we should add rather than subtract detail and ask the editors to show us the printed version before publication. The downside is that, with no restriction on space, all sorts of critical letters can be published on bmj.com, which may confuse readers and detract from the valid message of the research (that peer led education is a valid and potentially successful approach in health promotion).

Peter G Gibson senior staff specialist

Airway Research Centre, Department of

Respiratory and Sleep Medicine, John Hunter

Hospital, Newcastle 2310, Australia

Smita Shah director, Primary Health Care Education and Research Unit

Smita_Shah@wsahs.nsq.gov.au

Doungkarnol Sindhusake statistician

Department of Public Health and Community

Medicine, Westmead 2145, Australia

Han Wang statistician

Jennifer K Peat associate professor

Children's Hospital at Westmead, Westmead 2145, Australia

Richard L Henry professor of paediatrics

School of Paediatrics, University of New South

Wales, Randwick 2031, Australia

A longer version of this letter is available on bmj.com

1 Plummer W. Analysis should reflect the clustered study design [electronic response to Shah S et al. Effect of pee led programme for asthma education in adolescents: cluster randomised controlled trial]. www.bmj.com $/ \mathrm{cgi}$ eletters/322/7286/583\#EL1 (accessed 12 June 2001).

2 Henry RL, Gibson PG, Hazell J, Vimpani G, Leggatt R, Mowbray $\mathrm{C}$, et al. Integrated health and education input in the development of an educational package about asthm for schools. J Paed Child Health 1994;30:492-6.

3 Shah S, Mamoon H, Gibson PG. Peer-led health education for adolescents: 1. Development and implementation. Health Prom J Aust 1998;8:177-82.

4 Gibson PG, Shah S, Mamoon HA. Peer-led asthma education for adolescents. J Adolesc Health 1998;22:66-72.

\section{Alcohol and drug services have been patient centred for years}

EDITOR-Stewart's summary of and enthusiasm for a patient centred approach is most welcome. ${ }^{1}$ I believe that one additional feature of this approach should be addednamely, that it acknowledges the reality of patients accepting or rejecting our advice or treatment. Clinicians working with patients with alcohol and other drug problems, particularly those working in the harm reduction model, have known this for years.

The work of W R Miller, for example, has shown that the more confrontational (non-empathic, non-patient centred) the clinician the poorer the outcome. Previously, poor outcomes were taken as a sign of the patient's denial or unwillingness to changenow most clinicians (those working in the field of alcohol and other drug problems, at least) accept that these problems usually represent failure on the part of the therapist. The increasing evidence that most humans do not always "comply" with our treatments must surely make us as doctors more keen to enter our patients' world and mindset as a clinical priority, at least if we wish to achieve good health outcomes. Stewart's point, that the fact that some may not prefer a patient centred approach constitutes a false objection, is most important, since any clinician who rigidly adheres to any model as taught is, by definition, model centred, not patient centred.

Working with patients with alcohol and other drug problems, we often meet people who are very sick and who occasionally die from violence, overdose, or organ failure over the ensuing days or weeks. With respect to outcomes, it is a discipline as serious as any other. But we do not delude ourselves that we can do much more than attempt briefly to enter another person's world and possibly help make some positive changes if they wish. All health training and undergraduate programmes should incorporate significant exposure to the management of people who have problems with alcohol and other drugs, as a means to understand the person centred approach.

Rod MacQueen staff specialist, alcohol and other drugs

Orange, 2800, NSW, Australia

randjmac@ix.net.au

1 Stewart M. Towards a global definition of patient centred care. BMJ 2000;322:444-5. (24 February.)

\section{Minimal refereeing will lead to global equity of information}

EDITOR-The comment attributed to William Shulenberger in Smith's editorial on electronic publishing in science - that "minimal refereeing services" such as BioMed Central "may not get far because some scientific communities, particularly medicine, are nervous of minimal refereeing"-is pivotal. Minimal refereeing is only half the story. The other half concerns improving measures of the quality of published articles.

At the moment, our primary measure of quality is the brand name of the journal in which an article is published. This can lead to problems of validity, but also permits some top brand name journals to persist with restrictive policies on prior publication and copyright that block open access to primary research (the $B M J$ is the chief counterexample among the top journals because of its innovative approach to open access, open peer review, prior publication, copyright, and membership of PubMed Central; the Canadian Medical Association Journal is also a counterexample because of its policy on open access and membership of PubMed Central).

This "information blockade" deserves close ethical scrutiny, not least because it impedes access to health information for healthcare workers in developing countries. The inequities in global health represent the greatest ethical challenge in the world today. Underlying these inequities are inequities in health information.

The combination of minimal refereeing with maximal quality measurement is a way to break the information blockade. It decouples quality measurement of an article 
from the brand name of the journal in which it is published. This sets the stage for freeing the literature by changing the incentive structures of medicine and science to reward staff not on the basis of the brand name of the journal in which they publish but rather on the basis of the quality of the work itself.

Because minimal refereeing services such as BioMed Central potentially cover so many scholarly articles, it is with them that innovations in quality measurement will occur. A conceptual framework to guide this quality research, and a better developed version of the incentives argument, is at www.press.umich.edu/jep/ 06-02/singer.html

Minimal refereeing, coupled with innovation in quality measures and advocacy around incentive structures, represents one path to a future of global health information equity.

Peter A Singer Sun Life chairman in bioethics University of Toronto Joint Centre for Bioethics, Toronto, ON, Canada M5G 1L4 peter.singer@utoronto.ca

Competing interests: PAS is a member of the $B M$ J ethics committee, a subject adviser for BioMed Central medical ethics, and associate editor of the Canadian Medical Association Journal.

Smith R. Electronic publishing in science. $B M$ / 2001;322:627-8. (17 March.)

\section{Study should have reported more data about associated diseases}

EDITOR-In reporting their case-control study with 245 incident hip fractures, Pierfitte et al conclude that use of benzodiazepines does not confer any added risk. ${ }^{1}$ Unusually, plasma benzodiazepine concentrations were measured.

Fracture is considered to be the result of either an increased tendency to fall or an increased tendency to fracture, or both, so it would have been appropriate to gather information on history of fall. Use of benzodiazepines may lead to hip fracture by increasing the risk of falling and by affecting reaction time rather than by an intrinsic effect on bone. Did the authors obtain data on osteoporosis? How many patients were taking a drug prescribed because of osteoporosis?

The authors dismiss the role of dose and elimination half life. In contrast, we reported that dose and elimination of benzodiazepines have an independent and additive effect to increase the risk of falls ${ }^{2}$ and hip fracture. ${ }^{3}$ In addition, in a case-control study considering 9752 incident hip fractures we showed that, among benzodiazepines with a long half life, only oxidative agents are associated with an increased risk and that, at high doses, this is strongly related to age. ${ }^{3}$

The authors report that hypnotic and anxiolytic benzodiazepines were equally innocuous. This contradicts our report on 8851 cases of hip fractures. ${ }^{4}$ We showed that use of hypnotic benzodiazepines with a long half life confers a twofold increased risk, while there seems to be no added risk for users of anxiolytic agents. Our study confirmed an increased risk for users of lorazepam, although much smaller (odds ratio 1.2; 95\% confidence interval 1.1 to 1.7 ), but it also shows that caution is needed in the interpretation of odds ratios for individual agents. Among 571 users of temazepam (105 cases and 466 controls) the odds ratio was 1.0 (0.9 to 1.1), whereas in the present study (with eight users, equally divided between cases and controls) the odds ratio was 2.7.

Data about associated diseases are not reported. The issue is relevant because several diseases, such as diabetes mellitus and hypertension, seem to be characterised by increased bone loss and reduced bone mineral density. The authors reported on the effect of diuretics, tricyclic antidepressants, and antacids, yet other drugs may also be affecting outcome (K Lapane et al, annual meeting of American Geriatric Society, 1998. Recent studies have found that statins may protect against risk of fracture, whereas several anticonvulsants, corticosteroids, and oral anticoagulants may have a moderate effect to reduce bone mineral density.

Antonio Sgadari assistant professor

Giovanni Gambassi associate professor of medicine

Centro di Medicina dell'Invecchiamento Università Cattolica del Sacro Cuore Rome, Italy

giovanni_gambassi@rm.unicatt.it

Claudio Pedone assistant professor

Center for Gerontology and Health Care Research, Brown University School of Medicine, Providence, RI, USA

Graziano Onder assistant professor

Sticht Center on Aging, Wake Forest University

Medical School, Winston, Salem, NC, USA

Competing interests: None declared.

1 Pierfitte C, Macouillard G, Thicö̈pe M, Chaslerie A, Pehourcq F, Aïssou M, et al. Benzodiazepines and hip fractures in elderly people: case-control study. BMJ tures in elderly people:

2 Sgadari A, Bernabei R, Gambassi G, Landi F. Benzodiazepines and the risk for falls: a role for metabolic azepines and the risk for falls: a role

pathay? Gerontolgist 1998,98, A24 Sgadari A, Lapane KL, Mor V, Landi F, Bernabei R, Gambassi G. Oxidative and nor $\mathrm{V}$, Ladative benzodiazepines an he risk of femur fracture. J Clin Psychopharmacol 2000;20:234-9.

4 Sgadari A, Lapane KL, Mor V, Bernabei R, Gambassi G. Hypnotic and anxiolytic benzodiazepines and the risk of femur fracture J Gerontol-Med Sci (in press).

\section{Epidemiological surveillance of rubella must continue}

EDITOR-The description in 1941 by an Australian ophthalmologist of congenital cataract occurring after rubella in pregnancy was one of the first clearly demonstrated risk factors for congenital anomalies in humans. ${ }^{1}$ Several of the major ophthalmic long term effects of prenatal rubella infection, such as cataract, microphthalmos, and retinopathy, are recognisable at birth or in early infancy. ${ }^{2}$ Their diagnosis in children is recognised to be important in identifying the population at risk and in monitoring the burden of disease in developing countries.

In the United Kingdom, however, as in other industrialised countries with effective immunisation programmes, rubella has become an uncommon cause of ophthalmic disease. It was therefore an unexpected finding that in a national study of 248 children newly diagnosed with congenital cataract in the United Kingdom in the 12 months between October 1995 and September 1996, two had prenatal rubella infection. ${ }^{4}$ These two children were among 12 reported to the national congenital rubella surveillance programme after a resurgence of rubella infection in the United Kingdom in the spring of $1996 .{ }^{5}$ Seven of the 12 infants had ophthalmic manifestations. The surveillance programme received no reports of congenital rubella during 1997 or 1998, and only one in 1999.

We (GA and IRE) were therefore surprised to have three London born infants referred to us in the first quarter of 2001 with ophthalmic disease caused by congenital rubella, all with significant systemic manifestations. These three infants have been independently reported to the surveillance programme, together with another three, all born in the United Kingdom during 2000 and the first quarter of 2001. Only one of the six mothers was born in the United Kingdom; the other five women all acquired rubella infection early in pregnancy in their countries of origin.

These cases highlight the potential value of effective immunisation programmes in countries where they are currently lacking. They also serve as a timely reminder of the importance of maintaining the existing immunisation programme in the United Kingdom, and monitoring its effectiveness through epidemiological surveillance. This requires continued vigilance by health professionals, especially ophthalmologists and paediatricians, to ensure that all affected children are identified and appropriately notified.

Jugnoo Rahi clinical lecturer in ophthalmic epidemiology

Institute of Child Health, London WC1N 1EH

Gill Adams consultant ophthalmologist Isabelle Russell-Eggitt consultant ophthalmologist Moorfields Eye Hospital, London EC1V 2PD

Pat Tookey senior research fellow

Institute of Child Health, London WC1N 1EH

1 Gregg NM. Congenital cataract following German measles in the mother. Trans Ophthalmol Soc Aust 1941;3:35-46.

2 Givens KT, Lee DA, Jones T, Ilstrup DM. Congenital rubella syndrome: ophthalmic manifestations and associrubella syndrome: ophthalmic manifestations and associ-

ated systemic disorders. BrJ Ophthalmol 1993;77:358-63.

Eckstein M, Vijayalakshmi P, Killedar M, Gilbert C, Foster A. Aetiology of childho

J Ophthalmot 1996:80:628-32.

4 Rahi JS, Dezateux C, for the British Congenital Cataract Interest Group. Congenital and infantile cataract in the United Kingdom: underlying or associated factors. Invest Ophthalmol Vis Sci 2000;41:2108-14.

5 Tookey PA, Peckham CS. Surveillance of congenital rubella in Great Britain, 1971-96. BMJ 1999;318:769-70.

6 Tookey P, Molyneaux P, Helms P. UK case of congenital

rubella can be linked to Greek cases. BMJ 2000;321:766-7.

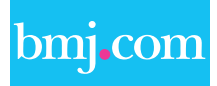

Rapid responses

Correspondence submitted electronically

is available on our website 